\title{
MODEL ELECTRIC CAR WITH WIRELESS CHARGING USING SOLAR ENERGY
}

\author{
Muhammad Osama Horani \\ Department of Mechatronics Engineering, SZABIST, Karachi, (Pakistan). \\ E-mail: m.osama.horani@gmail.com ORCID: https://orcid.org/0000-0002-0672-462X \\ Mariya Najeeb \\ Department of Mechatronics Engineering, SZABIST, Karachi, (Pakistan). \\ E-mail: mariynajeeb26@gmail.com ORCID: https://orcid.org/0000-0002-2317-7402 \\ Atif Saeed \\ Department of Mechatronics Engineering, SZABIST, Karachi, (Pakistan). \\ E-mail: m.atif@szabist.edu.pk ORCID: https://orcid.org/0000-0003-4369-2388
}

Recepción: 26/07/2021 Aceptación: 01/10/2021 Publicación: 14/12/2021

\section{Citación sugerida:}

Horani M. O., Najeeb, M., y Saeed, A. (2021). Model electric car with wireless charging using solar energy. 3C Tecnología. Glosas de innovación aplicadas a la pyme, 10(4), 89-101. https://doi.org/10.17993/3ctecno/2021. v10n4e40.89-101 


\section{ABSTRACT}

The current non-renewable energy-based transportation system is getting us places while simultaneously killing us. The global oil and gas markets are the most sizeable - 4677.45 billion-dollar industries - in the world in terms of revenue due to human dependency on fast transportation. In pre-industrial revolution times, the average rate of global temperature increase was 0.13-degrees Fahrenheit. The introduction of fossil fuel-based vehicles has more than doubled those numbers, thus resulting in accelerated global warming. Electrical vehicles have a few challenges of their own that we have discussed in this paper, finding solutions to them are based on Yoichi Hori's paper to make our model more energy efficient. Our model has been validated by researches done in the past, this paper combines the findings of formerly published papers to produce a working model of our current design with proof of concept. To reduce the carbon footprint of coal and fossil fuel-based electricity production, solar energy has been considered to charge the vehicle. It is not only an efficient choice, but it is also economical. It saves the consumer around $\$ 1778$ annually in fuel cost and $38.5 \mathrm{~g} / \mathrm{km}$ in carbon emissions. Using a wireless charging station solves a major UX design problem, making charging an effortless experience. This method is 88.05\% efficient at 31.5A. Supercapacitors have high power densities, therefore, being a good power source for the $\mathrm{EV}$ in theory, however, research shows that current supercapacitor technology is unable to perform as a standalone power source. Hence our model combines supercapacitors with conventional batteries to power the EV, additionally a break recovery system stores energy in the supercapacitor. This powers the car's acceleration. Our model priorities the use of materials that can be repurposed hence carbon-based electrodes are used - Graphene is a potential choice as it consists of high energy cycles.

\section{KEYWORDS}

Electric vehicles, Supercapacitors, Wireless power transfer, Solar energy, Sustainability, Power density, Climate change, Global warming, Resource management, Renewable energy. 


\section{INTRODUCTION}

Looking into the past, we can see how quickly we humans have taken advantage of our Earth's resources. The world was once a slow and simple place, where people travelled long distances through ships, walked to places, built everything with their bare hands. The first industrial revolution changed everything. We witnessed one of the biggest changes humanities had undergone in terms of mechanizing their work. The steam engine, one of the most important inventions in the history of mankind, although it had its caveats. Men started extracting coal exponentially and soon the entire industrial sector was running with the help of coal. At the end of the 18th century, we saw the second industrial revolution, where humans figured out ways to use gas, oil and electricity to their advantage.

Mankind, after just a few notable people's discoveries, had progressed substantially. Nearly all forms of the progress we humans have made, including computers, transportation, biology, economy have had an exponentially growing curve. Our planet is 4.5 billion years old; any system must reach an equilibrium after it has run its course with no interference.

The earth was in equilibrium for most of its existence. We, humans, have spent less than a per cent of earth's life here and have changed earth in unimaginable ways. What we do now will change the way we will be living in the next few decades. Huge changes are needed to be made for humans to survive on earth. Embracing sustainable goals will help us, humans, ensure a future for us all. The world will be a better place where humans don't take from the environment rather, live in conjunction with it or without it. Natural nonrenewable resources such as coal, oil, and gas, will run out shortly, so we will have to look for clean alternatives.

A sustainable environment will allow us to live a happy and healthy life. Reducing our carbon footprint is the least we can do to help. Engineers are one of the most important people when it comes to sustainable development, solving problems by applying their knowledge and refining existing technology to ensure that all our needs are met using sustainable practices. Engineers can design mass infrastructure, such 
as designing and building transportation systems that are good for the environment. They may help in finding new ways to recover and reuse existing resources to better make use of the waste we have.

Our research project tackles the biggest problem regarding the climate crisis, the transportation conundrum. Our transportation mediums are one of the largest contributors to global carbon emission levels. The model we have is an extension of an already working idea, the electric car. Our electric car uses supercapacitors to run which have a very high duty cycle, and are made using environmentally friendly resources. It is charged using solar panels through a wireless charging station. The goal of our project was to create something that has a closed-loop system, meaning there is no need for any external inputs to run our car. The solar panels take energy from the sun, provide it to the car, and the car can run without expelling any harmful gases, and with this, our cycle runs in a loop without damaging the environment.

\section{METHODOLOGY}

The design of our car is inspired by Tesla's Cyber truck, as it has a fairly minimal design while having a modern look. Our paper is an amalgamation of several other types of research which we reviewed extensively, to create a version of a future EV. We first worked on the idea of what realistically could be added to our version of the $\mathrm{EV}$ that would make it more complete, as a whole, for the user.

We looked into making our model primarily environmentally friendly, which would mean figuring out a way to charge it without using any fossil fuels or other unsustainable energy sources. Solar panels were the best and most efficient method to do that. We looked into papers that studied solar panels used for EV's to understand the economic as well as environmental factors. Charging time was another challenge, we wanted our power source to last as long as possible, consequently, we did not employ any of the fastcharging methods, as they would significantly reduce the battery's life span (Tomaszewska et al., 2019).

We explored ways to maximize battery efficiency by combining it with supercapacitors, which would 
additionally work as break recovery energy storage. To further improve the battery's efficiency, we allowed the supercapacitor to take over during periods of acceleration. The wireless power transfer system was added to give the user a seamless experience, where the car would enter the garage, it would start charging, being fully charged by the next day. This process helps combat range anxiety and gives users peace of mind. For each aspect of our car, we looked into what the prior research was telling us to ensure that our work was valid.

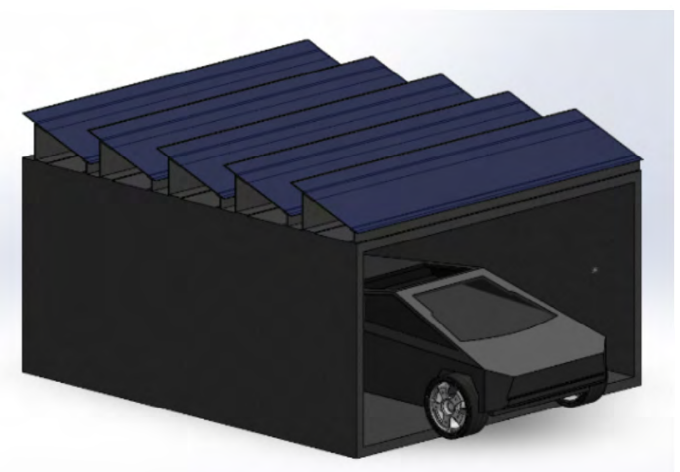

Figure 1. Wireless charging station and EV.

Source: own elaboration.

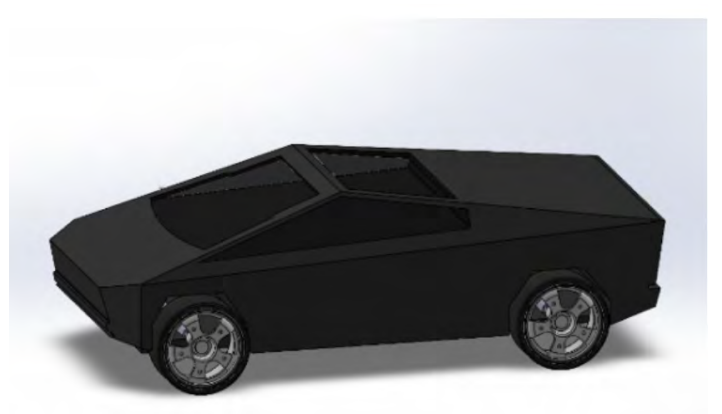

Figure 2. EV model inspired by Tesla Cyber Truck.

Source: own elaboration. 


\section{BACKGROUND STUDY}

When planning for this paper, we had to perform extensive research on every aspect of our model. Our idea was to build on the research done by Yoichi Hori (Hori, 2012). His research was regarding ideas for future EV development, where he mentioned how supercapacitors are the future due to their fast charging, high energy density, high duty cycle. In his paper he mentioned the use of quick charging systems, through a wireless power transfer system, discussing how cars would only need to stop for a few minutes for a full charge. Additionally. his paper considers motor usage, and several other technologies to use in conjunction with these systems. This paper provided a base to build on and produce a working model. After planning what we wanted to achieve, we had to verify proof of concept. A paper was published discussing their practical application of a wireless power transfer system for a sightseeing car (Ervin, 2015; Saeed et al., 2017). The car used a supercapacitor to hold its charge, charging after each tour. This research paper provided a detailed technical analysis of the wireless charging system while providing theoretical and practical findings.

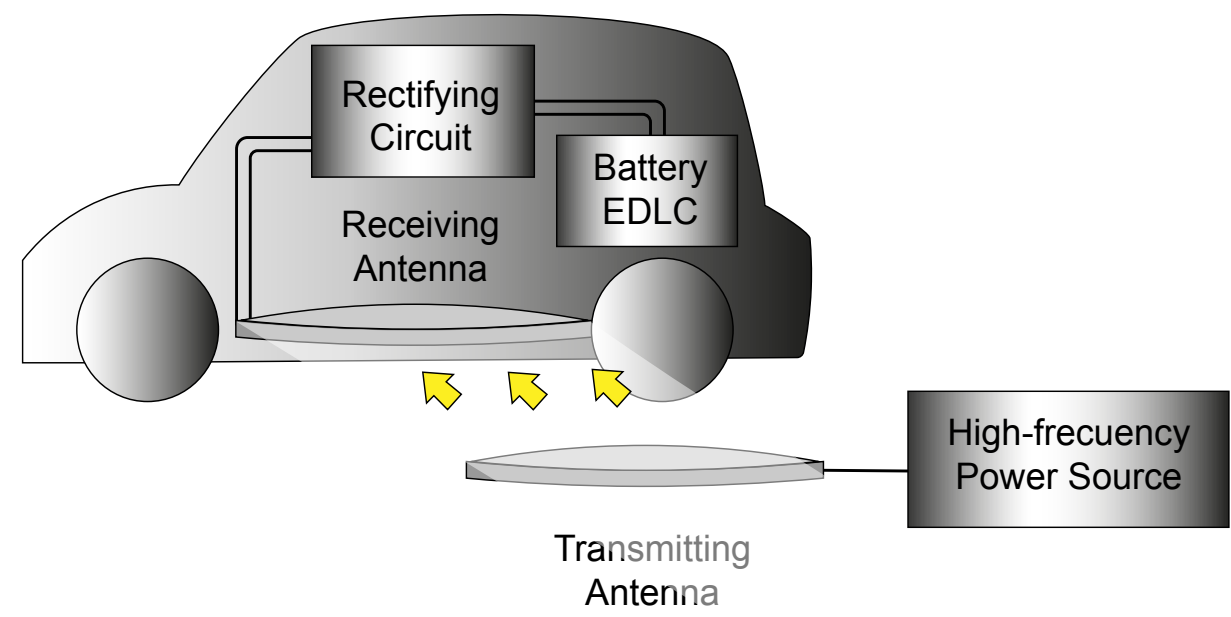

Figure 3. A representation of a wirelessly charged EV.

Source: (Hori, 2012). 
We had to consider if the current technology for supercapacitors is capable enough to run a car. The existing technology for supercapacitors is not quite adequate, however, development is continuing in the field, hinting at promising results. Currently, the best way to use supercapacitors is in conjunction with batteries. The research was done regarding this kind of amalgamation providing practical application of supercapacitor-battery run car while providing extensive information on each component in the system (Frenzel et al., 2011 ). It established all the advantages and disadvantages of the hybrid system and provided a clear plan of how this would be achieved.

The research was conducted regarding the idea of how feasible, using solar panels would be (Lee et al., 2017; Mouli et al., 2016). They discussed users wanting clean and green systems since electricity from companies uses up a substantial number of natural resources like coal and crude oil. The data regarding solar panels and their usage with EV's was immensely useful. They provided a complete analysis of solar energy production and how much an average car had charged given the size of the panels. Moreover, the papers considered solar power energy allocation helping realize how the power from the panels could be used for the home while the power for the car remains separately allocated for the car to charge it fully.

Throughout our research, we aimed to include components that were environmentally friendly in their making. The goal was to use materials that were repurposed or could be repurposed in the long run. The paper by Marichi et al. (2019), considered sustainable, clean energy and efficient storage devices. It predominantly explained the use of supercapacitors and how it was ideal that carbon-based waste materials be used to make electrodes for supercapacitors. This paper gave an excellent insight into how supercapacitors function and can work even better when made with carbon-based materials.

To know if supercapacitors would ever replace batteries in the future, we looked to Horn et al. (2019), where his paper explains the use of a supercapacitor and how it would be unviable to use them in their current state, though they did mention its uses in conjunction with batteries which was very useful as well. It provided a somewhat realistic prediction of how supercapacitors will progress in the future and was very inspired by the ideas it gave. 


\section{RESULTS}

Creating a model EV with features that were innovative, and convenient for real-world use was the goal of this paper. Dealing with such a complex design and feature set, our data-driven from several research papers has shown promising results with the way this car and its idea could function.

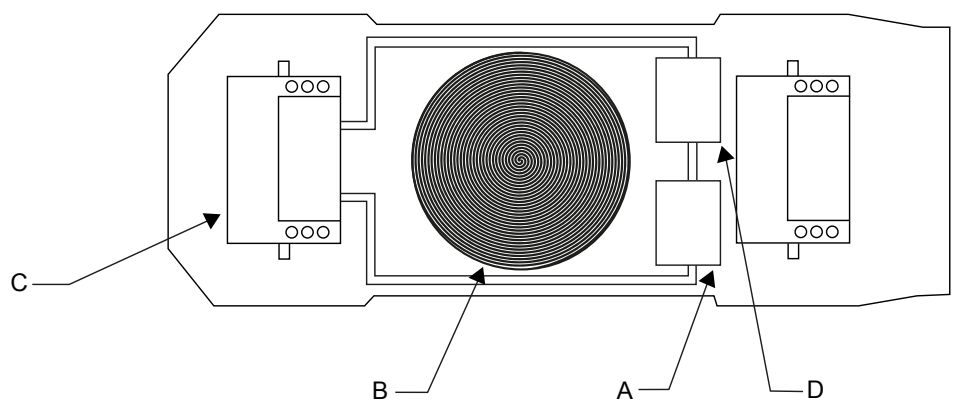

$$
\begin{aligned}
& \text { A - Supercapacitors } \\
& \text { B - receiving Antenna } \\
& \text { C - Inverter (Front and back) } \\
& \text { D - Rectifying Circuit }
\end{aligned}
$$

Figure 4. Internals of the model EV.

Source: own elaboration.

\subsection{COMBINATION OF SUPERCAPACITORS AND BATTERIES}

Despite supercapacitors having large duty cycles, an immensely high-power density and a long operating life, it is clear that present supercapacitor technology would be unable to make up for the requirement of driving for long distances. Hence the usage of batteries in conjunction with supercapacitors was proposed. Accelerating a car exerts strain on the battery causing it to consume energy at a faster rate, lowering its lifespan (Li \& Liu, 2019). A supercapacitor's high-power density allows it to supply and absorb large amounts of energy (Lee et al., 2017). We propose that whenever the car is accelerated for long periods, the supercapacitor is substituted as the energy source resulting in the battery operating only when speeds are somewhat stable. A system may be employed to smoothly alternate amongst the power sources without 
causing a delay. A similar idea was presented in Allègre et al. (2010), mentioning the energy absorbed by a brake energy recovery system would be stored in the supercapacitor, used to accelerate the car when it needs to move. Our idea allows the EV to take full advantage of the supercapacitor by giving it complete control of the car's acceleration - To achieve this future EVs require supercapacitors to have larger energy densities than the present ones. The use of Graphene could be presented as a potential solution for the energy density problem in supercapacitors (Ervin, 2015), although it may take time to develop.

\subsection{WIRELESS POWER TRANSFER SYSTEM}

Since, our power source consists of both batteries and supercapacitors, to increase charging efficiency, a charging system would need to be implemented that can take into account their equivalent resistance as they charge. We use findings from Li et al. (2017) to develop our design as it has proven to run at an efficiency of $88.05 \%$, with a constant current of $31.5 \mathrm{~A}$. Although, further study is required to create a more efficient design according to our requirements.

\subsection{USE OF SOLAR POWER FOR ELECTRIC VEHICLES}

Using an electric car instead of a gasoline car could result in an annual saving of \$1778 in fuel costs and reduce carbon emissions by an average of $38.5 \mathrm{~g} / \mathrm{km}$. In addition to this data, Mouli et al. (2016) discusses the various tax implications which gasoline-powered cars have to face, unlike EVs. Regardless of these economic and environmental advantages, power production in most countries is through burning fossil fuels. Charging a vehicle via electricity produced from nonrenewable sources accounts for $70.5 \mathrm{~g} / \mathrm{km}$ of $\mathrm{CO} 2$ per car on average. Electricity is a large expense in many countries, therefore factors to mass adoption issues of electric cars. Solar energy is the best solution, resulting in zero CO2 emissions as a whole, meanwhile being economically viable. The size and quantity of the solar panels would be as per the specifications and the manufacturer's recommendation. 


\section{CONCLUSIONS}

The goal of this project was to be able to realize our idea by researching and building upon proof-ofconcept papers. This entire project aims to create a self-sustaining closed-loop system. We were able to create an efficient design with eco-friendly materials and have its working be primarily sustainable. As our research dictated, supercapacitors in their current state will be best used in conjunction with a battery. A wireless charging station would make the switch from fuel-based vehicles to EV a significantly convenient experience. Using solar panels would save the consumers a considerable amount in electricity bills meanwhile reducing their carbon footprint. Making sustainable choices in all things is what we humans should aim for. As our life is short-lived, we must ensure future generations can have a life of comfort and ease

\section{REFERENCES}

Allègre, A. L., Bouscayrol, A., Delarue, P., Barrade, P., Chattot, E., \& El-Fassi, S. (2010). Energy storage system with supercapacitor for an innovative subway. IEEE Transactions on Industrial Electronics, 57(12), 4001-4012. https://doi.org/10.1109/TIE.2010.2044124

Ervin, M. H. (2015). Etching holes in graphene supercapacitor electrodes for faster performance. Nanotechnology, 26(23), 234003. https://doi.org/10.1088/0957-4484/26/23/234003

Frenzel, B., Kurzweil, P., \& Rönnebeck, H. (2011). Electromobility concept for racing cars based on lithium-ion batteries and supercapacitors. Fournal of Power Sources, 196(12), 5364-5376. https:// doi.org/10.1016/j.jpowsour.2010.10.057

Hori, Y. (2012). Novel EV society based on motor/ capacitor/ wireless - Application of electric motor, supercapacitors, and wireless power transfer to enhance operation of future vehicles. In 2012 IEEE MTT-S International Microwave Workshop Series on Innovative Wireless Power Transmission: Technologies, Systems, and Applications, IMWS-IWPT 2012 - Proceedings. https://doi.org/10.1109/ IMWS.2012.6215827 
Horn, M., MacLeod, J., Liu, M., Webb, J., \& Motta, N. (2019). Supercapacitors: A new source of power for electric cars? Economic Analysis and Policy, 61, 93-103. https://doi.org/10.1016/j. eap. 2018.08.003

Lee, S., Iyengar, S., Irwin, D., \& Shenoy, P. (2017). Shared solar-powered EV charging stations: Feasibility and benefits. In 2016 7th International Green and Sustainable Computing Conference, IGSC 2016. https://doi.org/10.1109/IGGG.2016.7892600

Li, L., \& Liu, Q. (2019). Acceleration curve optimization for electric vehicle based on energy consumption and battery life. Energy, 169, 1039-1053. https://doi.org/10.1016/j.energy.2018.12.065

Li, Z., Zhu, G., Jiang, J., Song, K., \& Wei, G. (2017). A 3-kW Wireless Power Transfer System for Sightseeing Car Supercapacitor Charge. IEEE Transactions on Power Electronics, 32(5), 3301-3316. https://doi.org/10.1109/TPEL.2016.2584701

Marichi, R. B., Sahu, V., Sharma, R. K., \& Singh, G. (2019). Efficient, Sustainable, and Clean Energy Storage in Supercapacitors Using Biomass-Derived Carbon Materials. In: Martínez, L., Kharissova, O., \& Kharisov, B. (eds.), Handbook of Ecomaterials. Springer, Cham. https://doi. org/10.1007/978-3-319-68255-6_155

Mouli, G. R. G., Leendertse, M., Prasanth, V., Bauer, P., Silvester, S., Van De Geer, S., \& Zeman, M. (2016). Economic and CO2 Emission Benefits of a Solar Powered Electric Vehicle Charging Station for Workplaces in the Netherlands. In 2016 IEEE Transportation Electrification Conference and Expo, ITEC 2016. https://doi.org/10.1109/ITEG.2016.7520273

Saeed, A., Ahmed, A., Junejo, F., \& Amin, I. (2017). Design of a small, cheap UUV for underwater exploration. In 2017 4th IEEE International Conference on Engineering Technologies and Applied Sciences (ICETAS), 1-5. https://doi.org/10.1109/ICETAS.2017.8277865 
Tomaszewska, A., Ghu, Z., Feng, X., O’Kane, S., Liu, X., Chen,J.,Ji, G., Endler, E., Li, R., Liu, L., Li, Y., Zheng, S., Vetterlein, S., Gao, M., Du, J., Parkes, M., Ouyang, M., Marinescu, M., Offer, G., \& Wu, B. (2019). Lithium-ion battery fast charging: A review. eTransportation, 1, 100011. https://doi.org/10.1016/j.etran.2019.100011 
